\title{
STUDY OF MACHINABILITY OF ELC STAINLESS STEEL X2CR20NI10MOTI AND ACCOMPANYING PHENOMENA IN THE CUTTING ZONE DURING DRILLING
}

\author{
JURKO, J[ozef] \& PANDA, A[nton]
}

\begin{abstract}
The basic hypothesis of this article focuses on the study of machinability with regard to the elimination of occurrence of poor - quality holes when drilling into new austenitic ELC (Extra Low Carbon) stainless steels $X 2 \mathrm{Cr} 20 \mathrm{Ni10MoTi}$. The problem of drilling holes with diameter $D=6$ to $10 \mathrm{~mm}$ resides in the fact that 20 to $30 \%$ of these holes do not comply with prescribed requested requirements. The cutting tools - screw drills as monoliths - get damaged and wear out. This article presents the results of experiments focusing on the study of the damage process in screw drills with diameter $d=8 \mathrm{~mm}$ when drilling into new austenitic ELC stainless steels X2Cr20Ni10MoTi.
\end{abstract}

Key words: tool wear, ELC steel, drilling, surface

\section{INTRODUCTION}

This article aims mainly to present the results of research within the framework of the defined hypothesis: a study of machinability of a new ELC stainless steels during drilling. with application of new structures on the cutting part of screw drills (in sintered carbide). Presented results also include an analysis of accompanying phenomena in the cutting zone and a discussion of the results of the measurement of some parameters during drilling.

\section{THE CUTTING TOOL WEAR}

Austenitic stainless steels are characterised by high strength, low heat conductivity, and a high degree of hardening of the machined surface after machining (Belluco \& De Chiffre, 2004). When machining stainless steels, we often note the occurrence of built-up edge; this phenomenon results in a reduction of tool life (Ceretti et al., 2009), (Paro et al., 2001). Cutting tool wear is the result of the combination of various wear mechanisms: abrasive, adhesive, diffuse, and chemical oxidation (Shaw, 2004).

Cutting zone is a summary term from the region during cutting. To properly describe the cutting zone it is necessary to describe the regions and test parameters (Clift et al., 1990): primary plastic deformation zone, secondary plastic deformation zone, tertiary plastic deformation zone, machined surface, its properties and integrity and the gradually-deformed region of the cut layer. The first zone between the chip and the workpiece, called the shear layer, divides the non-deformed region from the deformed chip under the angle of the shear layer, (indicated by $\Phi_{1}$ ) which is defined as identical to the boundary angle of deformation.

Tool wear influences the quality of surface finish of the products produced and thus, if unnoticed, can cause high costs. Wear of cutting edge is assistance combination of loading factors, that affect of cutting edge (Astakhov, 1998).

\section{EXPERIMENTAL PART}

\subsection{Technological system}

The set-up used contained the following components: a VMF-100 CNC machine new design of screw drill from sintered carbide with hydraulic holder. Diameter of screw drill $d=8.0 \mathrm{~mm}$. The materials to be machined were type of austenitic stainless steels with chemical composition listed in Table 1. The dimension of each piece was 50x20x150 mm. The cutting process employed was drilling of holes with dry machining, and the cutting speed defined at intervals of $50 \mathrm{~m}$ per min to $100 \mathrm{~m}$ per min, the feed advanced from intervals of $0.01 \mathrm{~mm}$ per rev. to $0.1 \mathrm{~mm}$ per rev. With regard to cutting tool life, the following criterion was applied: $V B_{\mathrm{K}}=0.2 \mathrm{~mm}$.

Cutting tool wear is a parameter we can examine by means of an optical light microscope. The examination of the cutting zone (i.e. interaction between tool and workpiece) is analyzed using Scanning Electron Microscopy (SEM).

\begin{tabular}{|c|c|c|c|}
\hline \multirow{5}{*}{ 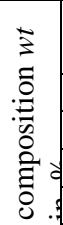 } & $\begin{array}{l}\text { Chemical } \\
\text { element }\end{array}$ & $\begin{array}{c}\text { Steel } \\
\text { X2Cr20Ni10MoTi }\end{array}$ & $\begin{array}{c}\text { Steel } \\
\text { Cr18Ni8 }\end{array}$ \\
\hline & carbon & 0.02 & 0.2 \\
\hline & chromium & 20.0 & 18.0 \\
\hline & nickel & 10.0 & 8.0 \\
\hline & manganese & 1.2 & 2.2 \\
\hline \multirow{4}{*}{ 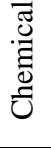 } & titanium & 0.8 & - \\
\hline & molybdenum & 0.1 & - \\
\hline & phosphorus & 0.025 & 0.03 \\
\hline & sulfur & 0.03 & 0.03 \\
\hline
\end{tabular}

Tab. 1. Chemical composition of stainless steels

\subsection{Experimental results and discussion}

The results of cutting zone evaluation under cutting conditions $\left(v_{\mathrm{c}}=60 \mathrm{~m} / \mathrm{min}\right.$ and feed $f=0.06 \mathrm{~mm}$ per rev.) are a definition of shear level angle. For X2Cr20Ni10MoTi steel $\Phi_{1}$ is $34^{\circ}$, for $\mathrm{Cr} 18 \mathrm{Ni}$ i8 steel $\Phi_{1}$ is $36^{\circ}$. Also important are the values of the depth of the plastically-deformed material of the machined surface of steel X2Cr20Ni10MoTi, shown figure 1., for steel $\mathrm{Cr} 18 \mathrm{Ni} 8$ shown figure 2.

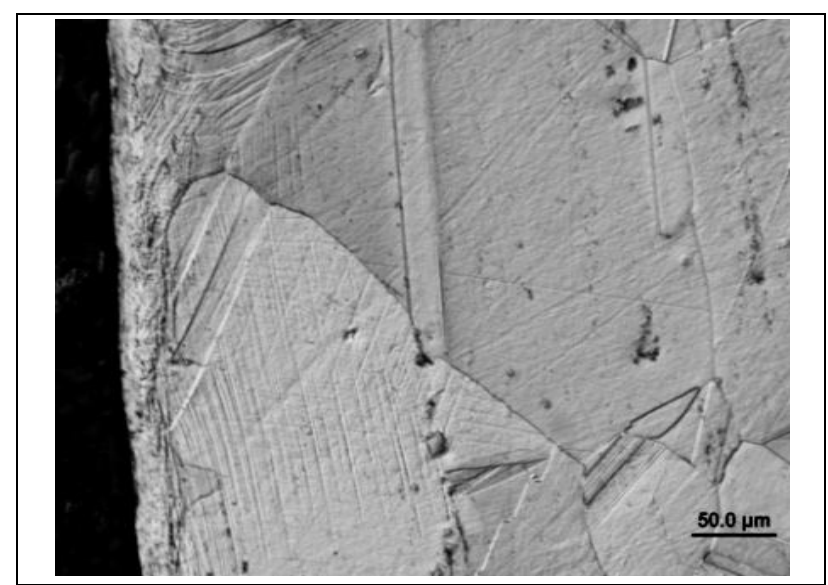

Fig. 1. Plastic deformation of $\mathrm{X} 2 \mathrm{Cr} 20 \mathrm{Ni} 10 \mathrm{MoTi}$ under the machined surface, $v_{\mathrm{c}}=60 \mathrm{~m} / \mathrm{min}, f=0.06 \mathrm{~mm}$ per rev. Etching: Villela

a) lokal plastic deformation, $\sim 28 \mu \mathrm{m}$

b) plastic deformation of austenite grain size, $\sim 140 \mu \mathrm{m}$ 


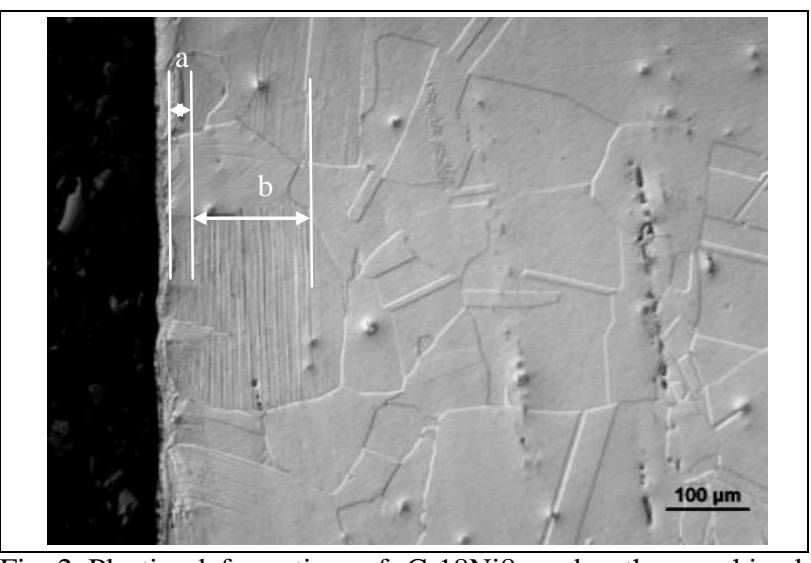

Fig. 2. Plastic deformation of $\mathrm{Cr} 18 \mathrm{Ni} 8$ under the machined surface, $v_{\mathrm{c}}=60 \mathrm{~m} / \mathrm{min}, f=0.06 \mathrm{~mm}$ per rev. Etching: Villela c) lokal plastic deformation, $\sim 36 \mu \mathrm{m}$

d) plastic deformation of austenite grain size, $\sim 224 \mu \mathrm{m}$

Stainless steels are influenced by charging due to intensive mechanical reinforcement during machining. The examination of reinforced surfaces can be carried out by measuring the micro-hardness of the bottom part of the fragment; indeed, the bottom part of the fragment can be considered as the most deformed fragment zone. The results of micro-hardness examination are reported in Figure 3 and Figure 4, these results are as follows:

- Cr18Ni8 steel: fragments are strongly deformed compared to $\mathrm{X} 2 \mathrm{Cr} 20 \mathrm{Ni} 10 \mathrm{MoTi}$ steel. Austenite fragment, bottom part, $v_{\mathrm{C}}=60 \mathrm{~m}$ per min, $305 \mathrm{HV}(20 \mathrm{~g})-$ if the bottom part of the fragment is measured: austenite $242 \mathrm{HV}(20 \mathrm{~g})$

- X2Cr20Ni10MoTi steel: $v_{\mathrm{c}}=60 \mathrm{~m}$ per min, austenite microhardness $228 \mathrm{HV}(20 \mathrm{~g})$-if the bottom part of the fragment is measured: austenite $228 \mathrm{HV}(20 \mathrm{~g})$

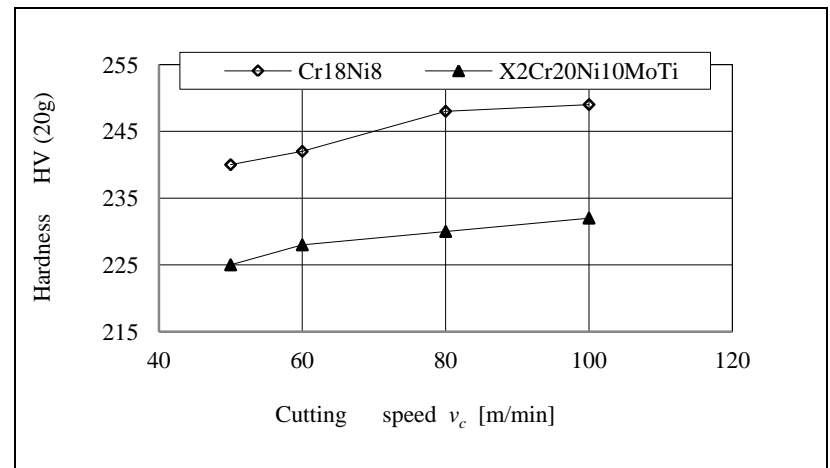

Fig. 3 Relation between machined workpiece micro-hardness and cutting speed, with feed $0.06 \mathrm{~mm}$ per rev.

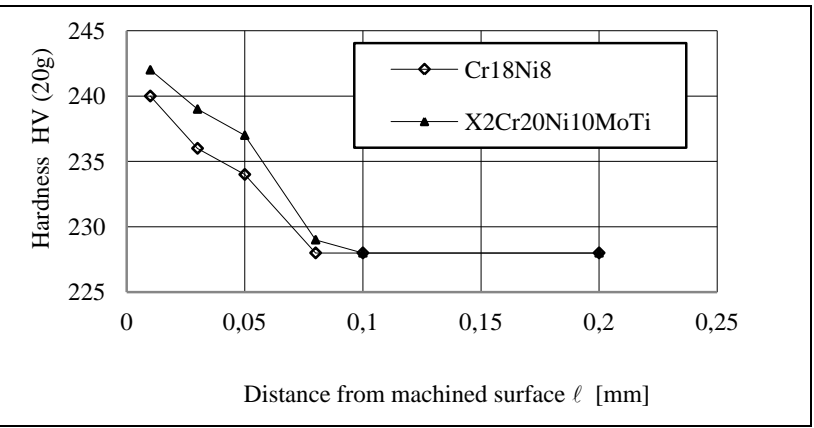

Fig. 4. Relation between machined workpiece micro-hardness and distance from machined surface, at cutting speed $60 \mathrm{~m}$ per min, with feed $0.06 \mathrm{~mm}$ per rev.

Cutting tool damage follows a chain of events. After drilling holes the cutting edge was influenced by the formation of Built Up Edge-BUE, as shown in Figure 5. The built-up edge in the face and major flank area might be the result of adhesive wear close to the cutting edge. One of the basic causes of such mechanisms is the quantity of heat generated in the cutting area when holes are made (here one of the main causes is represented by the low heat conductivity of steel). The tendency to generate built-up edges was more significant in the case of Cr18Ni8 steel than in the case of Cr20Ni10MoTi steel.

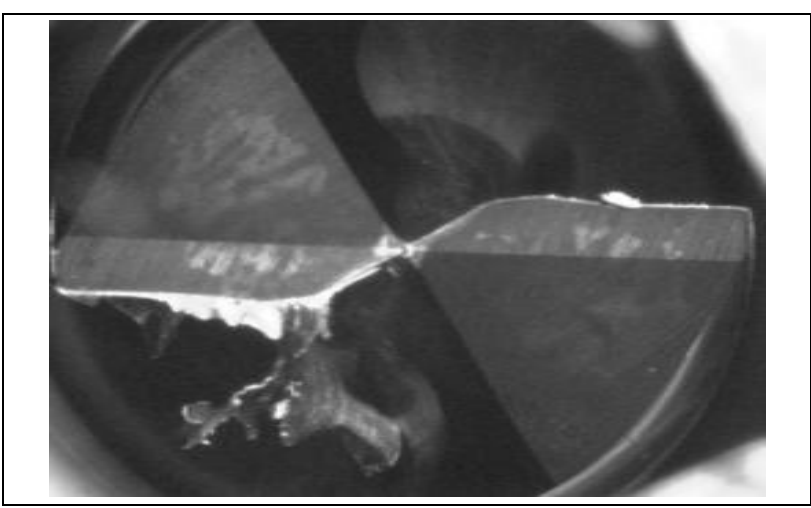

Fig. 5. Formation of built-up edges when drilling X2Cr20Ni10MoTi steel, at cutting speed $60 \mathrm{~m}$ per min, with feed in interval 0.04-0.06 $\mathrm{mm}$ per rev.

\section{CONCLUSION}

It is important for both theory and practical applications that essential conclusions come from measurement and analysis. The conclusions are as follows:

1. Defined coefficients for kinetic machining of austenitic stainless steels, whereby X2Cr20Ni10MoTi steel $K_{v}=0.68-0.70$, for Cr18Ni8 steel $K_{v}=0.62-0.65$ and for C45 steel $K_{\mathrm{v}}=1.0$.

2. Machinability of $\mathrm{Cr} 18 \mathrm{Ni} 8$ and $\mathrm{X} 2 \mathrm{Cr} 20 \mathrm{Ni} 10 \mathrm{MoTi}$ steels is influenced by the formation of BUE. Cr18Ni8 steel tends to form more BUE than X2Cr20Ni10MoTi.

3. BUE formation is caused by adhesive wear; in terms of cohesion, this fact indicates that the above mentioned mechanism is likely to be the predominant mechanism in the damaging process of sintered carbide tools when drilling into X2Cr20Ni10MoTi steel

\section{ACKNOWLEDGEMENTS}

The author express their thanks to the VEGA and KEGA grant agencies for supporting the research work and cofinancing the projects: VEGA Project n.1/0048/10 and KEGA Project n.3/7166/09.

\section{REFERENCES}

Astakhov, V.A. (1998). Metal Cutting Mechanics, CRC Press, ISBN-13: 978-0849318955, Boca Raton

Shaw, M.C. (2004). Metal Cutting Principles, Oxford University Press, ISBN-13: 978-0195142068, Oxford

Clift, S.E.; Hartley,P.; Sturgess,C.E.N. \& Rowe,G.W. (1990). Fracture prediction in plastic deformation processes. International Journal of Mechanical Sciences, Vol.32, No.1, January, 1990, pp.1-17, ISSN 0020-7403

Belluco, L. \& De Chiffre, L. (2004). Evaluation of vegetablebased oils in drilling austenitic stainless steels. Journal of Materials Processing Technology, Vol.148, No.2, May, 2004, pp.171-176, ISSN 0924-0136

Ceretti,E.; Giardini,C.A.; Filice,A.; Rizzuti,L. \& Umbrello,S.D. (2009) Diffusion wear modelling in 3D cutting process. International Journal of Machining and Machinability of Materials. Vol.6, No.1/2, June, 2009, pp.95-105, ISSN $1748-5711$

Paro, J.; Hänninen,H. \& Kauppinen,V. (2001). Tool wear and machinability of X5CrMnN1818 stainless steels. Journal of Materials Processing Technology, Vol.119, No.1-3, December, 2001, pp.14-20, ISSN 0924-0136 